\title{
Adjustment Dynamics of Bilateral Trade Flows: Theory and Evidence ${ }^{a}$
}

\author{
BENJAMIN JunG ${ }^{b}$
}

JEL-Classification: F14, F15

Keywords: international bilateral trade, gravity model, trust, dynamic panel data

\section{Introduction}

Static gravity models implicitly assume bilateral trade volumes to be at their steady-state levels. Bilateral trade flows, however, need some time to adjust to shocks. Evidence for dynamic adjustment is presented by EICHENGREen and Irwin (1998) for cross-section data, while De Grauwe and Skudelny (2000) and EGGER (2001a) apply dynamic panel data techniques.

Recent years have witnessed an increasing number of dynamic gravity applications. Micco et al. (2003) and De NARDis et al. (2008) study the dynamic effect of the Euro on bilateral trade, and Moser et al. (2008) and Martinez-Zarzoso et al. (2009) analyze the effect of German export promotion. All these studies, however, rely on ad hoc specifications of the dynamic gravity equation. Moreover, the adjustment rate is usually not considered explicitly. ${ }^{1}$ In some cases, test statistics cast doubt on the specifications. ${ }^{2}$

De Benedictis and Vicarelli (2005) motivate their dynamic gravity equation by the observation that "trade relationships between countries are affected [...]

a I am grateful to Jose de Sousa, Peter Egger, Gabriel Felbermayr, Wilhelm Kohler, Marcelo Olarreaga, Davide Sala, and Dieter Urban for stimulating discussions, and to participants at a Workshop at the Center for Economic Studies (CES) in Munich, at the Annual Meeting of the Swiss Society of Economics and Statistics in Geneva, and at the Annual Conference of the European Trade Study Group in Rome for comments. Part of the paper was written when I was visiting scholar at The Leverhulme Centre for Research on Globalisation and Economic Policy (GEP). Financial support from the German Research Foundation (DFG) through a $\mathrm{PhD}$ fellowship is gratefully acknowledged. All remaining errors are mine.

b Universität Hohenheim, 70593 Stuttgart, Germany. Tel.: +49711 459 23246. Email: b.jung@ uni-hohenheim.de.

1 An important exception is EgGer (2001b).

2 In De Nardis et al. (2008), e.g., the Hansen tests signal poor instruments. 
by the accumulation of invisible assets such as political, cultural and geographical factors" (p. 9). This formulation suggests that a potentially important determinant of trade costs has to be treated endogenously rather than exogenously. To the best of my knowledge, however, an 'invisible asset' has not been modelled explicitly yet.

The contribution of this paper is twofold. First, it introduces a trade-promoting 'invisible asset' into the standard KRUGMan (1980) model of international trade. The asset accumulates proportionally to bilateral trade volumes, and affects future trade flows positively through lower variable trade costs. In contrast to neoclassical growth models, asset accumulation does not involve saving but rather appears as a pure externality. The 'invisible asset' can be interpreted as trust which is created on the basis of what trading partners know about each other. Moreover, it can also be seen as knowledge about the foreign market that becomes, at least partly, known to all other firms. I then use this framework to theoretically derive a dynamic gravity equation and to discuss adjustment dynamics.

Second, the dynamic gravity regressions differ from those performed in previous studies. In order to account for time-varying determinants of bilateral trade flows such as aggregate expenditure or the overall price index, country-and-time effects are included. ${ }^{3}$ Following the empirical growth literature, I use data at fiveyear intervals. ${ }^{4}$ I do so to avoid finite sample bias that would arise if the number of periods in the sample were too large and to limit the country-and-time effects to a reasonable number. Moreover, the sample comprises information on potentially $96 \times 95$ country pairs instead of only OECD countries or a single anchor country. I back out the adjustment rate and compute long-run effects of trade reforms. To be more precise, the formation of free trade agreements (FTA) is addressed because FTAs aim at reducing "policy controlled barriers to the flow of goods, services, capital, labour, etc." (BAIER et al., 2008, p. 461) between two or more countries. Moreover, the last twenty years have witnessed an enormous increase in the number of FTAs, which gives sufficient variation in the data. ${ }^{5}$ The standard test statistics jointly signal validity of the estimation strategy. On average, trade flows take 3.5 years to close half the way from their initial positions to the steady state. This estimate is lower than the previous studies would imply.

Besides the dynamic gravity applications and the empirical growth literature, the present paper is related to recent advances on the role of trust and business networks for economic exchange. Guiso et al. (2009) report that an increase

3 See BALDwin et al. (2008) for a detailed discussion.

4 See, e.g., Bond et al. (2001).

5 See Baier and Bergstrand (2007) for a complete list of FTAs. 
in importers' trust towards the exporter boosts exports. The analysis, however, differs because they take trust as exogenously given, while in the present framework it is endogenized. Moreover, their analysis is limited to trade relationships between European countries because they draw on survey data. Krautheim (2008) introduces exporter networks in a model of trade with heterogeneous firms. Again, the analysis differs because in my framework networks reduce variable rather than fixed trade costs. Furthermore, Krautheim (2008) sets up a static model and does not consider adjustment dynamics.

The remainder of the paper is organized as follows. Section 2 introduces an 'invisible asset' into a multi-country monopolistic competition model of international trade. It then theoretically derives a dynamic gravity equation. Section 3 briefly discusses the estimation approach and the data. Results are presented in Section 4. The final section summarizes the results and sketches an interesting array of possible extensions.

\section{A Simple Dynamic Gravity Model}

In this section, I extent the standard KRUGMAN (1980) model of international trade. I introduce a trade-promoting 'invisible asset'. In contrast to the neoclassical growth literature, asset accumulation does not require saving of output but is assumed to accumulate in proportion to the volume of bilateral trade. It reduces variable trade costs and therefore positively affects trade flows in the future. The trade-creation effect arises as a pure externality. Within the theoretical framework, I derive a dynamic gravity equation, and discuss the relationship between the estimated trade persistence coefficient and the adjustment rate.

\subsection{The Theory-Based Static Gravity Model}

There exists a representative consumer with CES preferences over domestic and imported varieties of some differentiated good. The elasticity of substitution is given by $\sigma$. Imported varieties are subject to iceberg trade costs $T_{i j} \geq 1$. The (c.i.f.) value of country $i$ 's imports from country $j M_{i j}$ can be written as

$$
M_{i j}=N_{j} Y_{i}\left(\frac{T_{i j} p_{j}}{P_{i}}\right)^{1-\sigma},
$$


where $N_{j}$ is the number of products produced in country $j, Y_{i}$ is country $i$ 's aggregate expenditure, $p_{j}$ is the ex factory price of varieties produced in country $j$, and

$$
P_{i}=\left(\sum_{i=1}^{C} N_{i}\left(T_{i j} p_{j}\right)^{1-\sigma}\right)^{\frac{1}{1-\sigma}}
$$

is country i's overall price index; see Feenstra (2004) for the details of the derivation.

\subsection{Invisible Asset Accumulation}

We now endogenize trade costs $T_{i j}$ in order to make transparent how trade history shapes present bilateral trade. Assume that effective trade costs depend on a state variable $S_{i j}$ which measures the strength of an 'invisible asset', and can be interpreted as the level of trust between two countries. Trust is created on the basis on what trading partners know about each other. Hence, successful transactions nurture trust. This logic applies to relationships between input suppliers and final good producers as well as to relationships between final good producers and consumers. However, maintaining a certain level of trust requires repeated interaction. Otherwise trust is lost. Similarly, exchange of goods generates knowledge about trading opportunities, which is likely to become - at least partly - common, e.g., in a database of the Chamber of Commerce. Outdated information, however, is not longer useful.

Trade costs $T_{i j}$ are assumed to be decreasing and convex in the stock of the asset. ${ }^{6}$ If the stock of the asset approaches 0 , effective trade costs become prohibitively high. On the other hand, effective trade costs cannot fall short of unity. Asset accumulation takes place in proportion to the contemporaneous bilateral trade volume. However, the asset diminishes over time. Then, the asset grows at rate

$$
\dot{S}_{i j} / S_{i j}=\gamma M_{i j}\left[T\left(S_{i j}\right)\right] / S_{i j}-\delta,
$$

where the dot denotes differentiation with respect to time, the exogenous parameter $0<\gamma \leq 1$ measures to which extent bilateral trade feeds back to asset accumulation, and $0<\delta \leq 1$ denotes the depreciation rate. ${ }^{7}$ 


\subsection{Steady-State Trade Flow and the Time Path}

Figure 1 visualizes asset accumulation and depreciation graphically. The invisible asset accumulation curve, $\gamma M_{i j}\left[T\left(S_{i j}\right)\right] / S_{i j}$, is downward sloping. It asymptotes to infinity at $S_{i j}=0$, and approaches 0 as $S_{i j}$ tends to infinity. ${ }^{8}$ The invisible asset depreciation curve is a horizontal line at $\delta$. The vertical distance between the two curves equals the growth rate of the invisible asset; see equation (2). The asset reaches its steady-state level in a situation where asset accumulation by economic transactions exactly offsets asset depreciation. It is found at the intersection point of the two curves.

Figure 1: Invisible Asset Accumulation and Depreciation

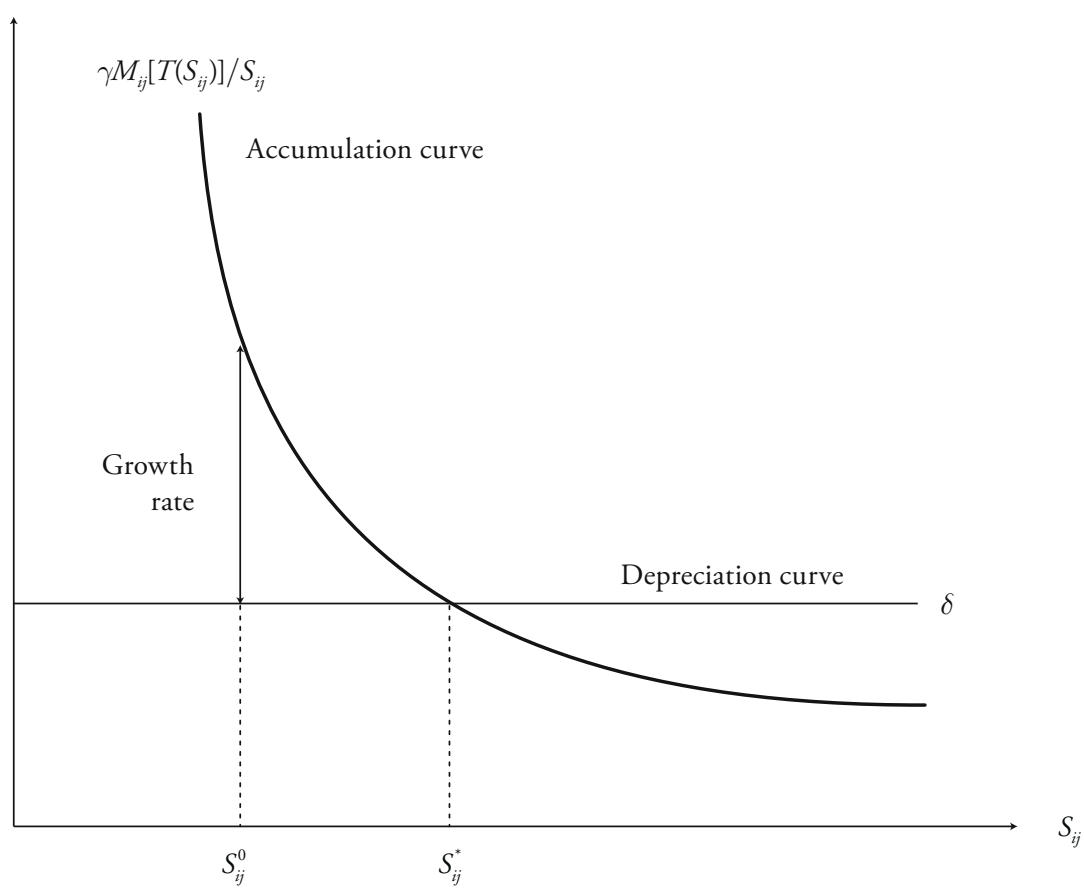

7 Note that equation(2) is similar to the fundamental equation in the neoclassical growth model, where capital is accumulated and depreciated; see, e.g., Barro and SAla-I-Martin (2003). For convenience, we express the model in continuous time, whereas in the empirical analysis we use data in discrete time.

8 Formally spoken, the trade cost function fulfills the inada conditions. 
In order to obtain a closed-form solution for the steady-state levels of the asset and the bilateral trade flow, trade costs are assumed to be log-linear in the level of the asset, i.e., $T\left(S_{i j}\right)=S_{i j}^{-\kappa} . \kappa$ is the (negative of the) elasticity of trade costs with respect to the asset. Then the conditions $\kappa>0$ and $\kappa<(\sigma-1)^{-1}$ guarantee that trade costs and the invisible asset accumulation curve respectively are decreasing and convex in the asset.

The steady-state level of the asset is determined from setting equation (2) equal to zero as

$$
S_{i j}^{*}=\left(\gamma \Gamma_{i j} / \delta\right)^{\frac{1}{1-\kappa(\sigma-1)}},
$$

where

$$
\Gamma_{i j} \equiv N_{j} Y_{i}\left(\frac{p_{j}}{P_{i}}\right)^{1-\sigma} \cdot 9
$$

It immediately follows from inserting the steady-state level of $S_{i j}$ into equation (1) that the steady-state trade flow is given by

$$
M_{i j}^{*}=\Gamma_{i j}\left(\gamma \Gamma_{i j} / \delta\right)^{\frac{\kappa(\sigma-1)}{1-\kappa(\sigma-1)}} .
$$

Thus, the steady-state trade flow $M_{i j}^{*}$ is a positive function of $\gamma$ and $\Gamma_{i j}$, and a negative function of $\delta$.

I can also characterize the time paths of $S_{i j}$ and $M_{i j}$. Define $s_{i j}=S_{i j}^{1-\kappa(\sigma-1)}$. Then rearranging equation (2) yields

$$
\frac{\dot{s}_{i j}}{1-\kappa(\sigma-1)}+\delta s_{i j}=\gamma \Gamma_{i j} .
$$

This is a first-order, linear differential equation in $s_{i j}$, the solution of which is given by

$$
s_{i j} \equiv S_{i j}^{1-\kappa(\sigma-1)}=\frac{\gamma \Gamma_{i j}}{\delta}+\left(\left[S_{i j}^{0}\right]^{1-\kappa(\sigma-1)}-\left[S_{i j}^{*}\right]^{1-\kappa(\sigma-1)}\right) e^{-\lambda t},
$$

9 Note that $\Gamma_{i j}$ is treated as fixed. Hence, I rule out equilibrium adjustments through the number of produced varieties, aggregate expenditure, the ex factory price, and the price index. This can be justified by assuming that each and every bilateral trade relationship is small enough not to affect aggregate variables. 
where $l \equiv(1-\kappa(\sigma-1)) \delta$. Hence, the gap between the level of the asset at an initial period in time $\left[S_{i j}^{0}\right]^{1-\kappa(\sigma-1)}$ and $\left[S_{i j}^{*}\right]^{1-\kappa(\sigma-1)}$ vanishes at the constant rate $\lambda .^{10}$

Similarly, the time path for the bilateral trade flow can be derived. It immediately follows from the solutions for the steady-state level of the asset $S_{i j}^{*}$ and the bilateral trade flow $M_{i j}^{*}$, that the growth rate of trade and the growth rate of the asset are linked by $\dot{M}_{i j} / M_{i j}=\kappa(\sigma-1) \dot{S}_{i j} / S_{i j}$. Moreover, it holds that $\ln \left(M_{i j} / M_{i j}^{*}\right)=\kappa(\sigma-1) \ln \left(S_{i j} / S_{i j}^{*}\right)$. A log-linear approximation of equation (2) around the steady state yields $\dot{S}_{i j} / S_{i j}=-\lambda \ln \left(S_{i j} / S_{i j}^{*}\right)$. By rearranging these expressions one obtains $\dot{M}_{i j} / M_{i j}=-\lambda \ln \left(M_{i j} / M_{i j}^{*}\right)$, which states that the adjustment rate of the trade flow is the same as that for the asset. Moreover, the solution to this differential equation in $\ln \left(M_{i j}\right)$ looks pretty much like a dynamic gravity equation once the steady-state trade flow $M_{i j}^{*}$ is substituted for by standard gravity controls

$$
\ln \left(M_{i j}\right)=\left(1-e^{-\lambda t}\right) \ln \left(M_{i j}^{*}\right)+e^{-\lambda t} \ln \left(M_{i j}^{0}\right) .
$$

Recall that the adjustment rate $\lambda$ is decreasing in the elasticity of substitution $\sigma$, and the elasticity of trade costs with respect to the invisible asset $\kappa$, and increasing in the depreciation rate $\delta$.

\subsection{Empirical Dynamic Gravity Equation}

The empirical gravity equation is derived from equation (4) and presented in discrete time

$$
\ln M_{i j t}=\alpha \ln M_{i j, t-1}+\xi F T A_{i j t}+v_{i t}+v_{j t}+\varepsilon_{i j t} .
$$

I proxy time-varying bilateral determinants of trade costs other than the invisible asset by a dummy $F T A_{i j t}$ which takes on one if countries $i$ and $j$ are in a free trade agreement at time $t$. The steady-state trade volume is further proxied by countryand-time effects $v_{i t}, v_{j t}$, which capture all time-varying country-characteristics like aggregate expenditure or price indices. The error term $\varepsilon_{i j t}$ can be decomposed

10 Note the similarity to the neoclassical growth model. Interestingly, the growth rate does not depend on the rate $\gamma$ at which the asset is accumulated. This result reflects two effects that exactly cancel out: On the one hand, a higher rate $\gamma$ leads to more asset accumulation and therefore to a higher growth rate of trade. On the other hand, it also raises the steady-state level of the asset, and thereby lowers its average product in the neighborhood of the steadystate. This, in turn, reduces the growth rate. 
into a country-pair specific component $v_{i j}$, which comprises geographical proximity like distance, and an idiosyncratic part $u_{i j t^{*}}$

$\xi$ equals $\bar{\xi}(\sigma-1)$, where $\bar{\xi}>0$ is the semi-elasticity of trade costs with respect to common FTA membership. The coefficient $\alpha$ measures the degree of trade flow persistence. $\alpha$ smaller than one signals that the invisible asset, and hence trade, indeed adjust to their steady-state values. A change in trade policy affects trade flows directly through $\xi$, and indirectly through adjustment of the invisible asset, which is captured by $\alpha .^{11}$

The coefficient $\alpha$ allows to quantify the adjustment rate $\lambda$. Comparing equations (4) and (5) shows that $\hat{\alpha}=e^{-\lambda \tau}$, which implies $\lambda=-\ln (\hat{\alpha}) / \tau$. $\tau$ is the time span between two observations. Furthermore, one can back out the time $\tau^{0.5}$ needed to close half the distance from the steady-state trade volume. It is determined by $e^{-\lambda \tau^{0.5}}=0.5$, which implies $\tau^{0.5}=-\ln (0.5) / \lambda$.

\section{Dynamic Panel Data Estimation and Data}

This section tackles issues that arise in the context of dynamic panel data estimation. Furthermore, it discusses data availability.

\subsection{How to Estimate a Dynamic Gravity Equation}

For many years, the gravity equation has been estimated using cross-section data. I start the analysis by including trade at some initial period into a standard cross-sectional regression. I control for the number of firms, the ex factory price of varieties, and the overall price index by country fixed effects. This approach is limited because trade in the initial period and contemporaneous trade may be highly correlated. Moreover, a cross-sectional approach does not allow to control for unobserved country-pair specific characteristics.

It is well known, that estimating dynamic gravity equation (5) by pooled ordinary least squares (OLS) or fixed effects (FE) leads to dynamic panel bias (NICKELL, 1981) due to the endogeneity of lagged trade. OLS and FE, however, provide useful guidance in the empirical analysis. Bond (2002) points out that $\hat{\alpha}^{O L S}$ and $\hat{\alpha}^{F E}$ are respectively biased upwards and downwards. The true $\alpha^{\text {true }}$, however, must fall into this bracket.

11 Note that $\alpha$ and $\xi$ are average and partial effects. I do not consider endogenous adjustments in the number of varieties, aggregate expenditure, the ex factory price, or the overall price index; see footnote 11 in BAIER and BERgstrand (2007) for this argument in a static setting. 
In order to deal with endogeneity, several strategies have been put forward to instrument the lagged dependent variable. Anderson and Hsiao (1981, 1982) propose a two-stage least squares estimator (2SLS). In a first step, the countrypair specific fixed effect $v_{i j}$ is eliminated by a first-difference transformation. However, $\Delta u_{i j t}$ is correlated with $\ln M_{i j t-1}$. Consistent estimates of $\alpha$ can be achieved if instrumental variables are available that are correlated with $\Delta \ln M_{i j t-}$ ${ }_{1}$ and at the same time orthogonal to $\Delta u_{i j t^{*}}$ The second lag of the level, $\ln M_{i j t-2}$ fulfils these requirements as long as the $u_{i j t}$ themselves are not serially correlated. ${ }^{12}$ The 2SLS estimator yields consistent results as long as the number of country-pairs is sufficiently large, whereas consistency does not hinge on the number of periods $T$. It is, however, inefficient, which is usually reflected in large standard errors.

In order to increase efficiency, Arellano and Bond (1991) propose to use lagged levels dated $t-2$ and earlier as instruments. ${ }^{13}$ Diff-GMM yields consistent estimates if $N \rightarrow \infty$ and $T$ is fixed. It suffers, however, from substantial finite sample bias that is in particular increasing in the number of instruments used. If the estimate for $\alpha$ is close to one or below the FE estimate, the Diff-GMM estimate is likely to be downward biased due to weak instruments. ${ }^{14}$

I perform two versions of a test for exogeneity of instruments. ${ }^{15}$ The Sargan statistic is the minimized value of the one-step GMM criterion function. Unfortunately, it is not robust to heteroskedasticity or autocorrelation. Hence, for onestep, robust estimation also the Hansen statistic is of interest, which is the minimized value of the two-step GMM criterion function. The Hansen test is robust; however, it can be greatly weakened by if too many instruments are used. I also

12 In the empirical part, I explicitly test for serial autocorrelation.

13 I either additionally include the level dated $t-3$ or the levels dated $t-3$ and $t-4$. In both cases, the set of instruments is "collapsed" into a single column in order to limit the number of instruments. Recent dynamic panel data applications adapt this strategy, e.g., BECK and Levine (2004) or Carkovic and Levine (2005). See Roodman (2009) on the superiority of collapsed instruments.

14 Note that in the present paper we do not report results from System-GMM estimation, which relies on stricter assumptions than Diff-GMM and 2SLS. Note further that common FTA membership is treated as exogenous. Using a Wooldridge test, BAIER and Bergstrand (2007) cannot reject exogeneity of the FTA dummy in the presence of country-pair fixed effects. Timeinvariant country-pair characteristics are tackled by a first-differentiating transformation.

15 The null hypothesis of the test is that the excluded instruments are valid, i.e., instruments are uncorrelated with the error term and correctly excluded from the estimated equation. The test statistic is distributed chi-squared with $L-K$ degrees of freedom, where $L$ is the number of excluded instruments and $K$ is the number of regressors. A rejection casts doubt on the validity of the instruments. 
test for serial autocorrelation in the error terms, which would render the instruments invalid; see Arellano and Bond (1991).

\subsection{Data}

As common in the empirical growth literature, I use data at five-year intervals in order to avoid finite sample bias that would arise if the number of periods were too large. Moreover, this strategy helps to limit the number of countryand-time effects.

Bilateral trade data come from the Direction of Trade Statistics (DoTS). Zero (and missing) trade flows are excluded. ${ }^{16}$ This implies, that only trade relationships are considered, where the initial level of trust suffices to observe positive trade flows.

BAIER and BERgSTRAND (2007) provide information on FTA membership for a sample of $96 \times 95$ country-pairs covering the years $1960,1965, \ldots, 2000{ }^{17}$ Data on geographical and cultural proximity like distance, contiguity, colonial ties, and use of a common language come from the CEPII database. GDP data are not required, since GDPs as well as price indices are covered by countryand-time effects.

I construct a balanced sample which covers as many country pairs as possible. ${ }^{18}$ Therefore, the analysis is restricted to the period 1980-2000. Hence, I end up with $N=3572$ country pairs and $T=5$ periods. ${ }^{19}$

\section{Results from a Dynamic Gravity Approach}

In this section, the speed of adjustment to steady-state trade volumes is backed out. Moreover, long-run effects of FTA formation obtained from static and dynamic regressions are compared.

16 In the body of the paper, we present results for import flows. The Appendix shows the corresponding estimations for exports.

17 The bilateral trade policy dataset is kindly made available at http://web.mac.com/baier_family/ iWeb/Site\%202/Data.html. Table 4 in the Appendix lists the countries included.

18 A balanced sample is not necessary but preferable because Diff-GMM sets missing entries in the instrument matrix to zero.

19 The total number of country pairs decreases substantially if longer periods are covered. 
Table 1: Cross-Section Data Regressions

\begin{tabular}{|c|c|c|c|c|}
\hline Dependent variable: & $\begin{array}{r}\text { limports } \\
(1) \\
\text { OLS }\end{array}$ & $\begin{array}{c}\text { (2) } \\
\text { OLS }\end{array}$ & $\begin{array}{c}\text { (3) } \\
\text { OLS }\end{array}$ & $\begin{array}{c}(4) \\
\text { OLS }\end{array}$ \\
\hline Distance & $\begin{array}{l}-1.274^{* * *} \\
(-28.14)\end{array}$ & $\begin{array}{l}-0.789^{* * *} \\
(-18.35)\end{array}$ & $\begin{array}{l}-0.852^{* * *} \\
(-21.53)\end{array}$ & $\begin{array}{l}-0.916^{* * *} \\
(-21.47)\end{array}$ \\
\hline Contiguity & $\begin{array}{l}0.125 \\
(0.73)\end{array}$ & $\begin{array}{l}-0.0103 \\
(-0.07)\end{array}$ & $\begin{array}{l}0.0596 \\
(0.41)\end{array}$ & $\begin{array}{l}0.0735 \\
(0.51)\end{array}$ \\
\hline Common language & $\begin{array}{l}0.649^{* * *} \\
(8.39)\end{array}$ & $\begin{array}{l}0.320^{* * *} \\
(4.75)\end{array}$ & $\begin{array}{l}0.379^{* * *} \\
(5.61)\end{array}$ & $\begin{array}{l}0.376^{* * *} \\
(5.36)\end{array}$ \\
\hline FTA & $\begin{array}{l}0.182^{*} \\
(1.92)\end{array}$ & $\begin{array}{l}0.0732 \\
(1.01)\end{array}$ & $\begin{array}{l}0.138^{*} \\
(1.79)\end{array}$ & $\begin{array}{l}0.116 \\
(1.45)\end{array}$ \\
\hline Imports 1990 & & $\begin{array}{l}0.477^{* * *} \\
(18.61)\end{array}$ & & \\
\hline Imports 1985 & & & $\begin{array}{l}0.403^{* * *} \\
(20.52)\end{array}$ & \\
\hline Imports 1980 & & & & $\begin{array}{c}0.352^{* * * *} \\
(17.56)\end{array}$ \\
\hline $\mathrm{R} 2$ & 0.834 & 0.876 & 0.867 & 0.860 \\
\hline Adjustment rate & & $7.40 \%$ & $6.07 \%$ & $5.22 \%$ \\
\hline Half-life time & & 9.365 & 11.43 & 13.29 \\
\hline
\end{tabular}

$\mathrm{N}=3572$ country-pairs. Robust t-values in parentheses. ${ }^{* * *}$ and ${ }^{*}$ indicate significance at respectively $1 \%$ and $10 \%$ level. All regressions include a comprehensive set of exporter- and importer fixed effects. Adjustment rate quantifies how much of distance to steady state is closed each year. Half-time life time reports time needed to close half the gap to steady state.

\subsection{Adjustment Rate}

Table 1 presents the results of estimating the dynamic gravity equation (5) using data for the year 2000 and for different initial periods, namely 1990, 1985, and 1980. All regressions include exporter and importer fixed effects. For the sake of comparability, column (1) provides the results from a static regression with the restriction $\alpha=0$. All coefficients appear with their expected signs, although some of them only marginally significant. The distance coefficient is close to -1. In column (2), trade in 1990 is included in the set of explanatory variables. As expected, the coefficient turns out to be highly significant. Moreover, sizes of 
the other coefficients shrink since they now represent impact rather than longrun effects. The focus is on the adjustment rate, which is also shown in Table 1 and amounts to $7.4 \%$; see column (2). This means that $7.4 \%$ of the distance to the steady-state trade volume is closed each year. Then, half of the gap is closed after approximately 9 years. ${ }^{20}$

Columns (3) and (4) replicate the exercise for different initial periods. The strong positive relationship between the trade volume in an initial period and contemporaneous trade remains intact. The implied adjustment rates are slightly lower when considering trade in 1985 (6\%) and in 1980 (5.2\%).

Table 2 turns to dynamic panel data regressions. In all the regressions, countryand-time effects are included in order to account for the fact that the number of varieties, the aggregate expenditure, the price of a variety, and the overall price index potentially vary over time; see BALDwIN et al. (2008) for a detailed discussion. Column (1) provides the results of a pooled OLS regression where a five-year lag of trade is included. Coefficients of time-invariant explanatory variables are suppressed. Lagged trade appears to be highly statistically significant. The implied adjustment rate is approximately $10.2 \%$. As pointed out by NICKEL (1981), the estimated coefficient suffers from severe upward bias. The estimated adjustment rate then provides a lower bound to the true effect. In column (2), unobserved country-pair characteristics are controlled for by means of a withintransformation (fixed effects estimator). The lagged trade coefficient is rendered insignificant, which represents a downward bias toward zero.

Column (3) proceeds with estimates obtained from a 2SLS approach. The second lag of the trade value in levels is used as an instrument for the lagged endogenous variable; see ANDERson and Hsiao (1981, 1982). The F-statistic of the first stage regression is about 20, which signals a sufficient fit; see STAIGER and STOCK (1997). The estimated lagged trade coefficient falls into the range between the POLS and the FE estimate as the true effect should; see Bond (2002) for more details. Moreover, it turns out to be highly statistically significant. Hence, inefficiency of the estimator does not seem to be an issue in the regression. The Arellano-Bond tests for AR(1) and AR(2) in the (differenced) residuals do not hint on invalidity of instrument. The implied adjustment rate amounts to $23 \%$. Then, half the distance to the steady-state trade volume is closed after approximately 3 years.

Columns (4) and (5) show Diff-GMM estimation results for different lag structures in the instrument matrix. Sargan and Hansen tests of overidentifying

20 Recall that $\lambda=-\ln (\hat{\alpha}) / 10$. 
Table 2: Dynamic Panel Data Regressions

\begin{tabular}{|c|c|c|c|c|c|}
\hline \multicolumn{6}{|c|}{ Dependent variable: Bilateral imports } \\
\hline & (1) & (2) & (3) & (4) & (5) \\
\hline & POLS & $\mathrm{FE}$ & $2 S L S$ & Diff-GMM & Diff-GMM \\
\hline \multirow[t]{2}{*}{ Lagged trade } & $0.652^{* * *}$ & 0.0303 & $0.317^{* * *}$ & $0.320^{* * *}$ & $0.313^{* * *}$ \\
\hline & $(63.33)$ & $(1.58)$ & $(9.73)$ & $(9.90)$ & $(9.65)$ \\
\hline \multirow[t]{2}{*}{ FTA } & $0.118^{* * *}$ & $0.322^{* * *}$ & $0.349^{* * *}$ & $0.339^{* * *}$ & $0.332^{* * *}$ \\
\hline & $(3.12)$ & $(4.64)$ & $(5.97)$ & $(5.67)$ & $(5.57)$ \\
\hline \multirow{2}{*}{\multicolumn{2}{|c|}{ Instruments }} & & $\mathrm{t}-2$ & $\mathrm{t}-2, \mathrm{t}-3$ & $\mathrm{t}-2, \mathrm{t}-3$ \\
\hline & & & & & $t-4$ \\
\hline Adjustment rate & $8.55 \%$ & n.a. & $23.0 \%$ & $22.8 \%$ & $23.2 \%$ \\
\hline Half-life time & 8.103 & n.a. & 3.017 & 3.042 & 2.984 \\
\hline FTA long-run effect & 0.339 & n.a. & 0.511 & 0.499 & 0.483 \\
\hline \multicolumn{2}{|l|}{$\operatorname{AR}(1)$ test (p-value) } & & 0.000 & 0.000 & 0.000 \\
\hline \multicolumn{2}{|l|}{$\operatorname{AR}(2)$ test (p-value) } & & 0.810 & 0.798 & 0.836 \\
\hline \multicolumn{2}{|l|}{ Sargan test (p-value) } & & & 0.215 & 0.128 \\
\hline \multicolumn{2}{|l|}{ Hansen test ( $\mathrm{p}$-value) } & & & 0.393 & 0.341 \\
\hline
\end{tabular}

Balanced sample of $\mathrm{N}=3572$ country-pairs and $\mathrm{T}=5$ periods. Robust $\mathrm{t}$-values in parentheses. ${ }^{* * *}$ indicates significance at $1 \%$ level. All regressions include a comprehensive set of country-and-time effects. OLS includes controls for distance, contiguity, and common language (all not shown). One-step GMM results. Adjustment rate quantifies how much of distance to steady state is closed each year. FTA treated exogenous. Instruments collapsed into a single column. Half-time life time reports time needed to close half the gap to steady state. Long-run effects obtained from deviding short-run effect through one minus coeffcient on lagged endogenous variable.

restrictions do not cast doubt on these specifications. The point estimate $\hat{\alpha}$ is remarkably stable across specifications (3) to (5). In all regressions, it amounts to approximately 0.32 with a t-value close to $10{ }^{21}$ Put differently, the half-life time of adjustment, which is the time for half the initial gap to be eliminated, is about 3 years. ${ }^{22}$ It takes about six years to close three-quarters of the gap to vanish.

How do the findings compare to previous estimates? The basic specification in EGGER (2001a) implies an adjustment rate of $47 \%$ per year. His sample covers 15 European countries, and the period 1986-1996. Micco et al. (2003) present

21 Recall that $\lambda=-\ln (\hat{\alpha}) / 5$.

22 Solving $e^{-\lambda \tau^{*}}=0.5$ for $\tau^{*}$ yields $\tau^{*}=-\ln (0.5) / \lambda$. 
dynamic panel estimation results for a sample of trade relationships between 22 developed countries. Using a period comparable to ours, 1980-2002, their estimates imply an adjustment rate of about $55 \%$ a year, which is much higher than my result. Their estimates, however, are likely to be biased for the following reasons. First, they use yearly data, which may lead to finite sample bias. Second, they do not account for multilateral resistance terms. When it comes to the shorter period (1992-2002), the Arellano-Bond test for AR(2) in differences signals invalidity of the instruments. The misspecification is also reflected in the coefficient of the lagged endogenous variable, which would imply an adjustment rate of $137 \%$.

The estimates reported in De Nardis et al. (2008) potentially suffer from misspecification. In all regressions, the Hansen tests signal weak instruments. The implied convergence rate would be about 29\%. Moser et al. (2008) and Martinez-Zarzoso et al. (2009) focus on German exports. Using the estimates reported by the former, the adjustment rate is about $71 \%$, whereas the latter find adjustment rates of $39 \%$.

A dynamic approach has also been applied by EgGer and Merlo (2007) to stocks of outward foreign direct investments. The sample mainly consists of OECD countries and covers the period 1980-2001. The p-values of the Hansen tests cast doubt on the validity of the test; see Roodman (2009). Columns $\left(a_{1}\right)$ and $\left(a_{2}\right)$ of their Table 1 correspond to an adjustment rate of $78 \%$.

For per capita income, CASELli et al. (1996) find an adjustment rate of about $10 \%$ per year, which implies a half-life time of 7 years. Hence, trade flows take about half the time to close half the way from their initial position to their steady-state levels as compared to per capita income. This result seems plausible, since the adjustment of trade does not face barriers like the installation of physical capital.

\subsection{Short- and Long-Run FTA Effects}

Not only the lagged trade coefficient is statistically significant and stable across the preferred specifications, but also the estimated coefficient for common FTA membership; see columns (3) to (5) in Table 2. The point estimate amounts to approximately 0.34 with a t-value close to 6 . Thus, FTA formation corresponds to $e^{0.34}-1=40.5 \%$ trade creation on impact. The long-run, however, is much higher and amounts to $e^{0.50}-1=65 \% .{ }^{23}$ This is the case because the formation

23 The long-run effect is obtained by dividing the short-run effect through one minus the effect of the lagged endogenous variable. 
of an FTA corresponds to a positive trade shock which induces accumulation of the invisible asset. A higher stock of the asset, in turn, implies lower trade costs. The long-run effect comprises both, the impact effect, and the indirect effect that runs through asset accumulation.

Table 3: Static Panel Data Regressions

\begin{tabular}{|c|c|c|}
\hline \multicolumn{3}{|c|}{ Dependent variable: Bilateral imports } \\
\hline & (1) & (2) \\
\hline & FD & FD \\
\hline FTA & $\begin{array}{l}0.301^{* * *} \\
(6.01)\end{array}$ & $\begin{array}{l}0.328^{* * *} \\
(6.27)\end{array}$ \\
\hline FTA (1st lag) & & $\begin{array}{l}0.127^{* *} \\
(2.16)\end{array}$ \\
\hline Sum FTA & 0.301 & 0.455 \\
\hline $\mathrm{R} 2$ & 0.164 & 0.159 \\
\hline \multicolumn{3}{|c|}{$\begin{array}{l}\text { Balanced sample of } \mathrm{N}=3572 \text { country-pairs and } \mathrm{T}=5 \\
\text { periods. Robust t-values in parentheses. }{ }^{* * *} \text { and } \\
\text { indicate significance at } 1 \% \text { and } 5 \% \text { levels. All regres- } \\
\text { sions include a comprehensive set of country-and-time } \\
\text { effects. }\end{array}$} \\
\hline
\end{tabular}

The long-run FTA effect obtained from the dynamic regressions is of comparable size to the corresponding long-run effect obtained from static regressions, which are presented in Table $2 .{ }^{24}$ The first difference estimator (FD) yields a statistically significant FTA coefficient of about 0.3; see column (1). BAIER and BERGSTRAND (2007), however, argue that FTAs are 'phased-in' and propose to include lagged FTA dummies in order to account for this institutional nature of FTAs. I do so in column (2) and obtain a total FTA effect of $e^{0.455}-1=58 \%$, which is very close to the long-run trade creation effect obtained from the dynamic regressions.

The results presented for bilateral imports are robust to the use of export values; see Tables 5, 6, and 7 in the Appendix.

24 The country-pair fixed effect $v_{i j}$ is eliminated by a first-difference transformation of equation (5). I then restrict $\alpha=0$. 


\section{Concluding Remarks}

Although the recent decade has witnessed an increasing number of empirical dynamic gravity applications, there is no basic theoretical framework to derive a dynamic version of the gravity equation. In this paper, I have proposed a model that casts variable trade costs as endogenously determined by a trade-promoting 'invisible asset' which can be interpreted as trust. The model generates insights in what can be a driving force behind staggered adjustment of bilateral trade flows and what the adjustment rate looks like.

I present empirical evidence that is consistent with the model. That is, asset accumulation matters for trade. Approximately $23 \%$ of the gap from the initial to the steady-state trade flow are closed each year. This estimate is at the lower end of what previous studies would imply. The main difference is that I follow the empirical growth literature and use data at five-year intervals. Trade flows adjust faster to steady-state levels than per capita income. This is not surprising, since the accumulation of an 'invisible asset' does not require installation of physical capital.

Asset accumulation also matters for the impact of FTAs on trade. While estimates obtained from a static gravity equation suggest that FTAs will increase two member countries' trade about $40 \%$ in the long-run, the corresponding long-run effect obtained from a dynamic estimation that takes into account asset accumulation amounts to approximately $65 \%$. An estimate of comparable size can only be obtained from static regressions once lagged FTA dummies are included.

The present paper allows for an interesting array of extensions. First, I have only considered aggregate trade flows. It would be possible to estimate the adjustment rate for different commodity groups. ${ }^{25}$ One can conjecture that commodity groups not only differ in their elasticity of substitution, but also in the elasticity of trade costs with respect to the asset $\kappa$ and the depreciation rate $\delta$. Moreover, I have restricted the analysis to FTA membership but one can include other timevarying proxies for trade policy, too.

Second, estimates of the long-run FTA trade-creation effects obtained from a dynamic gravity specification and a static one where a lagged FTA dummy is included are of identical size. BAIER and BERgSTRAND (2007) motivate the inclusion of lagged FTA dummies by the observation that FTAs are usually 'phasedin' over a certain period. This reflects the institutional nature of FTAs and has

25 RAUCH (1999) considers three kinds of commodity groups, namely differentiated goods, reference-priced goods, and exchange-traded goods. 
to be taken as exogenously given. The present paper proposes a model where variable trade costs endogenously adjust to trade policy shocks but does not consider 'phasing-in'. The truth is likely to lie somewhere in between, and it would be desirable to empirically examine the relative importance of either channel.

Third, I only report average effects. However, there exists interesting variation across country pairs. Geographically or culturally proximate country pairs are likely to be initially endowed with a high level of the asset. Everything else equal, this shifts the invisible asset accumulation curve to the right, resulting in a lower invisible asset growth rate. Proximate countries, however, tend to have lower physical transportation costs. This would shift the invisible curve upwards, implying a higher growth rate. From a theoretical point of view, the net effect is ambiguous. Which channel is more important is an empirical question which I leave for further research.

\section{Appendix}

Table 4: List of Countries

\begin{tabular}{|c|c|c|c|}
\hline Albania & Ecuador & Jamaica & Poland \\
\hline Algeria & Egypt & Japan & Portugal \\
\hline Angola & El Salvador & Kenya & Romania \\
\hline Argentina & Ethiopia & Korea, Republic of & Saudi Arabia \\
\hline Australia & Finland & Madagascar & Senegal \\
\hline Austria & France & Malawi & Sierra Leone \\
\hline Bangladesh & Gabon & Malaysia & Singapore \\
\hline Belgium & Gambia & Mali & Spain \\
\hline Bolivia & Germany & Mauritania & Sri Lanka \\
\hline Brazil & Ghana & Mauritius & Sudan \\
\hline Bulgaria & Greece & Mexico & Sweden \\
\hline Burkina Faso & Guatemala & Morocco & Switzerland \\
\hline Cameroon & Guinea-Bissau & Mozambique & Syrian Arab Republic \\
\hline Canada & Guyana & Netherlands & Thailand \\
\hline Chile & Haiti & New Zealand & Trinidad and Tobago \\
\hline China & Honduras & Nicaragua & Tunisia \\
\hline Colombia & Hong Kong & Niger & Turkey \\
\hline Congo & Hungary & Nigeria & Uganda \\
\hline Congo, Dem. Rep. & India & Norway & United Kingdom \\
\hline Costa Rica & Indonesia & Pakistan & United States of America \\
\hline Cote d'Ivoire & Iran & Panama & Uruguay \\
\hline Cyprus & Ireland & Paraguay & Venezuela \\
\hline Denmark & Israel & Peru & Zambia \\
\hline Dominican Republic & Italy & Philippines & Zimbabwe \\
\hline
\end{tabular}


Table 5: Cross-Section Data Regressions

\begin{tabular}{|c|c|c|c|c|}
\hline \multicolumn{5}{|c|}{ Dependent variable: Bilateral exports } \\
\hline & (1) & $(2)$ & (3) & $(4)$ \\
\hline & OLS & OLS & OLS & OLS \\
\hline Distance & $\begin{array}{l}-1.212^{* * *} \\
(-28.30)\end{array}$ & $\begin{array}{l}-0.696^{* * *} \\
(-17.60)\end{array}$ & $\begin{array}{l}-0.828^{* * *} \\
(-19.91)\end{array}$ & $\begin{array}{l}-0.868^{* * *} \\
(-20.58)\end{array}$ \\
\hline Contiguity & $\begin{array}{l}0.358^{* *} \\
(2.26)\end{array}$ & $\begin{array}{l}0.0222 \\
(0.18)\end{array}$ & $\begin{array}{l}0.113 \\
(0.84)\end{array}$ & $\begin{array}{l}0.190 \\
(1.42)\end{array}$ \\
\hline Common language & $\begin{array}{l}0.643^{* * *} \\
(9.08)\end{array}$ & $\begin{array}{l}0.294^{* * *} \\
(5.15)\end{array}$ & $\begin{array}{l}0.389^{* * *} \\
(6.31)\end{array}$ & $\begin{array}{l}0.387^{* * *} \\
(6.14)\end{array}$ \\
\hline FTA & $\begin{array}{l}0.293^{* * *} \\
(3.23)\end{array}$ & $\begin{array}{l}0.130^{*} \\
(1.88)\end{array}$ & $\begin{array}{l}0.240^{* * *} \\
(3.09)\end{array}$ & $\begin{array}{l}0.219^{* * *} \\
(2.84)\end{array}$ \\
\hline Imports 1990 & & $\begin{array}{l}0.517^{* * *} \\
(24.79)\end{array}$ & & \\
\hline Imports 1985 & & & $\begin{array}{l}0.382^{* * *} \\
(20.65)\end{array}$ & \\
\hline Imports 1980 & & & & $\begin{array}{l}0.338^{* * *} \\
(19.11) \\
\end{array}$ \\
\hline $\mathrm{R} 2$ & 0.825 & 0.879 & 0.860 & 0.854 \\
\hline Adjustment rate & & $6.60 \%$ & $6.41 \%$ & $5.42 \%$ \\
\hline Half-life time & & 10.50 & 10.81 & 12.79 \\
\hline
\end{tabular}

$\mathrm{N}=3921$ country-pairs. Robust $\mathrm{t}$-values in parentheses. ${ }^{* * *},{ }^{* *}$, and ${ }^{*}$ indicate significance at respectively $1 \%, 5 \%$, and $10 \%$ level. All regressions include a comprehensive set of exporter- and importer fixed effects. Adjustment rate quantifies how much of distance to steady state is closed each year. Half-time life time reports time needed to close half the gap to steady state.

Table 6: Dynamic Panel Data Regressions

Dependent variable: Bilateral exports

(1)

$(2)$

(3)

(4)

(5)

\begin{tabular}{lccccc} 
& POLS & FE & 2SLS & Diff-GMM & Diff-GMM \\
\hline Lagged trade & $0.670^{* * *}$ & $0.062^{* * *}$ & $0.368^{* * *}$ & $0.371^{* * *}$ & $0.378^{* * *}$ \\
& $(79.54)$ & $(3.91)$ & $(12.84)$ & $(14.11)$ & $(14.49)$ \\
FTA & $0.207^{* * *}$ & $0.345^{* * *}$ & $0.294^{* * *}$ & $0.290^{* * *}$ & $0.296^{* * *}$ \\
& $(5.96)$ & $(5.09)$ & $(4.76)$ & $(4.65)$ & $(4.73)$ \\
\hline Instruments & & & $\mathrm{t}-2$ & $\mathrm{t}-2, \mathrm{t}-3$ & $\mathrm{t}-2, \mathrm{t}-3$, \\
& & & & $\mathrm{t}-4$ \\
\hline
\end{tabular}


Table 6 (continued)

\begin{tabular}{lccccc}
\hline \multicolumn{1}{l}{ Dependent variable: Bilateral exports } & & & & \\
& $(1)$ & $(2)$ & $(3)$ & $(4)$ & $(5)$ \\
& POLS & FE & 2SLS & Diff-GMM & Diff-GMM \\
\hline Adjustment rate & $8.0 \%$ & $55.6 \%$ & $20.0 \%$ & $19.8 \%$ & $19.5 \%$ \\
Half-life time & 8.654 & 1.246 & 3.467 & 3.495 & 3.562 \\
\hline FTA long-run effect & 0.627 & 0.368 & 0.465 & 0.461 & 0.476 \\
\hline AR(1) test (p-value) & & & 0.000 & 0.000 & 0.000 \\
AR(2) test (p-value) & & & 0.377 & 0.382 & 0.374 \\
Sargan test (p-value) & & & & 0.485 & 0.0653 \\
Hansen test (p-value) & & & & 0.663 & 0.249 \\
\hline
\end{tabular}

Balanced sample of $\mathrm{N}=3921$ country-pairs and $\mathrm{T}=5$ periods. Robust $\mathrm{t}$-values in parentheses. ${ }^{* * *}$ indicates significance at $1 \%$ level. All regressions include a comprehensive set of country-and-time effects. OLS includes controls for distance, contiguity, and common language (all not shown). One-step GMM results. Adjustment rate quantifies how much of distance to steady state is closed each year. FTA treated exogenous. Instruments collapsed into a single column. Half-time life time reports time needed to close half the gap to steady state. Long-run effects obtained from deviding short-run effect through one minus coeffcient on lagged endogenous variable.

Table 7: Static Panel Data Regressions

\begin{tabular}{lcc}
\hline \multicolumn{3}{l}{ Dependent variable: Bilateral exports } \\
& $\begin{array}{l}(1) \\
\text { FD }\end{array}$ & $\begin{array}{c}(2) \\
\text { FD }\end{array}$ \\
\hline FTA & $\begin{array}{c}0.287^{* * *} \\
(5.97)\end{array}$ & $\begin{array}{l}0.290^{* * *} \\
(5.74)\end{array}$ \\
FTA (1st lag) & & $\begin{array}{c}0.117^{* *} \\
(2.16)\end{array}$ \\
\hline Sum FTA & 0.287 & 0.402 \\
\hline R2 & 0.173 & 0.165
\end{tabular}

Balanced sample of $\mathrm{N}=3921$ country-pairs and $\mathrm{T}=5$ periods. Robust t-values in parentheses. ${ }^{* * *}$ and ${ }^{* *}$ indicate significance at $1 \%$ and $5 \%$ levels. All regressions include a comprehensive set of country-and-time effects. 


\section{References}

Anderson, T. W., and C. Hsiao (1981), "Estimation of Dynamic Models with Error Components", Journal of the American Statistical Association, 76, pp. 598-606.

Anderson, T. W., and C. Hsiao (1982), "Formulation and Estimation of Dynamic Models Using Panel Data", Journal of Econometrics, 18, pp.47-82.

Arellano, M. and S. Bond (1991), "Some Tests of Specification for Panel Data: Monte Carlo Evidence and An Application to Employment Equations", The Review of Economic Studies, 58, pp. 277-297.

Baier, S., and J. H. Bergstrand (2007), "Do Free Trade Agreements Actually Increase Member's International Trade?”, Journal of International Economics, 71, pp. 72-95.

Baier, S., J. H. Bergstrand, P. Egger, and P.A. McLaughlin (2008), “Do Economic Integration Agreements Actually Work? Issues in Understanding the Causes and Consequences of the Growth of Regionalism", The World Economy, 31 (4), pp. 461-497.

Baldwin, R., V. DiNino, L. Fontagne, R. De Santis, and D. Taglioni (2008), "Study on the Impact of the Euro on Trade and Foreign Direct Investment", European Economic and Monetary Union Working Paper 321.

Barro, R. J., and X. Sala-i-Martin (2003), Economic Growth. Cambridge, MIT Press.

Beck, T., and R. Levine (2004), "Stock Markets, Banks, and Growth: Panel Evidence", Journal of Banking and Finance, 28 (3), pp.423-442.

Bond, S. (2002), "Dynamic Panel Data Models: A Guide to Micro Data Methods and Practice", Portuguese Economic Journal, 1 (2), pp. 141-162.

Bond, S., A. Hoeffler, and J. Temple (2001), "GMM Estimation of Empirical Growth Models", CEPR Discussion Paper 3048.

Carkovic, M., and R. Levine (2005), "Does Foreign Direct Investment Accelerate Economic Growth?”, in: T. H. Moran, E. M. Graham, and M. Blomström, Does Foreign Direct Investment Promote Development? Washington, DC: Institute for International Economics and Center for Global Development.

Caselli, F., G. Esquivel, and F. Lefort (1996), "Reopening the Convergence Debate: A New Look at Cross-Country Growth Empirics", Journal of Economic Growth, 1, pp.363-389.

De Benedictis, L., and C. Vicarelli (2005), "Trade Potentials in Gravity Panel Data Models", Topics in Economic Analysis \& Policy, 5 (1), Art. 20.

De Grauwe P., and F. Skudelny (2000), "The Impact of EMU on Trade Flows", Weltwirtschaftliches Archiv/Review of World Economics, 136, pp.381-402. 
De Nardis, S., R. de Santis, and C. Vicarelli (2008), “The Euro's Effects on Trade in a Dynamic Setting", The European Journal of Comparative Economics, 5 (1), pp. 73-85.

Egger, P. (2001a), "European Exports and Outward Foreign Direct Investment: A Dynamic Panel Data Approach", Weltwirtschaftliches Archiv/Review of World Economics, 137 (3), pp.427-449.

Egger, P. (2001b), "European Integration in Trade and FDI: A Dynamic Perspective", CESifo Forum, 2 (2), pp.30-35.

Egger, P., and V. Merlo (2007), "The Impact of Bilateral Investment Treaties on FDI Dynamics”, The World Economy, 30 (10), pp. 1536-1549.

Eichengreen, B., and D. Irwin (1998), "The Role of History in Bilateral Trade Flows", in: J. Frankel (ed.), The Regionalization of the World Economy, University of Chicago Press.

Feenstra, R. C. (2004), Advanced International Trade: Theory and Evidence. Princeton, Princeton University Press.

Guiso, L., P. Sapienza, and L. Zingales (2009), "Cultural Biases in Economic Exchange", Quarterly Journal of Economics, forthcoming.

Krautheim, S. (2008), "Gravity and Information: Heterogeneous Firms, Exporter Networks and the 'Distance Puzzle", European University Institute, Mimeo.

Krugman, P. (1980), "Scale Economies, Product Differentiation, and the Pattern of Trade", American Economic Review, 70 (5), pp. 950-959.

Martinez-Zarzoso, I., F. Nowak-Lehmann Danzinger, S. Klasen, and M. Larch (2009), "Does German Development Aid Promote German Exports?", German Economic Review. forthcoming.

Micco, A., E. Stein, G. Ordonez (2003), "The Currency Union Effect on Trade: Early Evidence from EMU”, Economic Policy, 18 (37), pp.315-356.

Moser, C., T. Nestmann, and M. Wedow (2008), "Political Risk and Export Promotion: Evidence from Germany”, The World Economy, 31 (6), pp. 781-803.

Nickel, S. (1981), "Biases in Dynamic Models with Fixed Effects", Econometrica, 49 (6), pp. 1417-1426.

Rauch, J. E. (1999), “Networks Versus Markets in International Trade”, Journal of International Economics, 48 (1), pp.7-35.

Roodman, D. M. (2009), "A Note on the Theme of Too Many Instruments", Oxford Bulletin of Economics and Statistics, 71 (1), pp. 135-158.

Staiger, D., and J. H. Sтоск (1997), "Instrumental Variables Regression with Weak Instruments", Econometrica, 65 (3), pp. 557-586. 


\section{SUMMARY}

In this paper, I introduce a trade-promoting 'invisible asset' into the standard KRUGMAN (1980) model of international trade. It can be interpreted as trust that accumulates as an externality in proportion to successful international transactions. I use this framework to theoretically derive a dynamic gravity equation and to discuss adjustment dynamics. I provide new evidence on adjustment rates of bilateral trade flows. On average, $23 \%$ of the gap to the steady-state trade flow are closed each year. However, dynamic regressions yield long-run trade policy effects which are comparable to static estimates. 